\title{
How and Why Teenagers Use Video Chat
}

\author{
Tatiana Buhler, Carman Neustaedter, and Serena Hillman \\ School of Interactive Arts and Technology, Simon Fraser University \\ $250-13450102^{\text {nd }}$ Avenue \\ Surrey, BC, Canada, V3T 0A3 \\ [tda6, carman_neustaedter, shillman]@sfu.ca
}

\begin{abstract}
Teenagers are increasingly using video chat systems to communicate with others, however, little research has been conducted to explore how and why they use the technology. To better understand this design space, we present the results of a study of twenty teenagers and their use of video chat systems such as Skype, FaceTime, and Google Hangouts. Our results show that video chat plays an important role in helping teenagers socialize with their friends after school and on weekends where it allows them to see emotional reactions and participate in activities like shared homework sessions, show and tell, and performances over distance. Yet video chat is also used to engage in more private activities such as gossiping, flirting, and even the viewing of sexual acts. This presents an interesting design challenge of supporting teen use of video chat while mitigating privacy and parental concerns.
\end{abstract}

\section{Author Keywords}

Teenagers; video chat; video conferencing; social media

\section{ACM Classification Keywords}

H.5.3 [Information interfaces and presentation]: Group and Organization Interfaces - Computer Supported Cooperative Work;

\section{INTRODUCTION}

For many adolescents, connection with friends for socialization, relationship-building, and 'hanging out' now takes place online $[4,22]$. The social expectations and pressures that are created by constant connectivity are also evident amongst teens [19]. Given this, a large amount of research has focused on how teenagers make use of a variety of communication technologies. This includes text messaging [8], instant messaging [9,10], and social networking sites such as Facebook [1,4,22].

Over the last several years, we have seen the use of video chat for communication amongst family and friends rapidly proliferate with the availability of free video conferencing systems like Skype, Apple FaceTime, and Google Hangouts. This has resulted in studies exploring the ways in

Permission to make digital or hard copies of all or part of this work for personal or classroom use is granted without fee provided that copies are not made or distributed for profit or commercial advantage and that copies bear this notice and the full citation on the first page. To copy otherwise, or republish, to post on servers or to redistribute to lists, requires prior specific permission and/or a fee.

CSCW'13, February 23-27, 2013, San Antonio, Texas, USA

Copyright 2013 ACM 978-1-4503-1331-5/13/02...\$15.00. which video chat is used by families with children $[2,13,16]$, grandparents and grandchildren [25], long distance partners [24], etc. In 2012, a study showed that $37 \%$ of teenagers aged 12 to 17 used video chat [17]; however, we have yet to see any studies that specifically document how and why teenagers use such systems. Without this, we do not know how video chat supports (or does not) the needs of this unique demographic and how such systems could be better designed.

For this reason, we have conducted a study with twenty teenagers - between thirteen and eighteen years of agewho use video chat to communicate with their friends or family at varying frequencies. Our results outline the ways in which video chat is used by teenagers, when and why teenagers choose to use video chat over other technologies, and what challenges they face in using the technology. To foreshadow, like prior studies of adult use of video chat $[2,6,13,16,24]$, teenagers valued being able to see their friends, they engaged in open connections in order to share activities longer term, and some teenagers even engaged in sexually explicit activities over video chat. Like pre-teens' usage of asynchronous video [12], teenagers also engaged in 'Show and Tell' sessions and 'Performing Acts'.

Beyond this, teens also showed new and different patterns of usage. Video calls were most often spontaneous, multiperson calls were more frequent, and, most fundamental, teenagers had a more localized sense of distance than adults. That is, video chat was about 'hanging out' with neighborhood friends, rather than trying to feel closer to people across long distances (as found for adults $[2,6,16]$ ). Overall, our results point to interesting challenges focused on designing video chat systems to better support the needs of teenagers while also mitigating parental concerns

First, we outline the related work on video chat and teenagers' use of technology for communication. Second, we describe our interview study methodology. Third, we outline our results. We conclude by discussing our results and what they mean for the design of future video communication systems for teenagers.

\section{RELATED WORK}

To ground our study, we outline the related literature on studies of teenagers' use of technology. Some of these studies are several years old and, given the rapidly changing use of technology, practices may have changed since then. Following this, we describe studies of video chat systems. 


\section{Text Messaging}

As of 2008, 71\% of American youth aged 12-17 had a mobile phone where $85 \%$ used their mobile phones to send text messages or 'text' [19]. Texting is very popular among teenagers because it is fast and efficient, convenient, and private [10]. That is, teenagers feel they can communicate with friends without the eyes and ears of parents, siblings, or classmates knowing about their activities [8,22], though there is care to ensure texts do not always remain on one's phone for surreptitious browsing [20]. Texting most commonly occurs between people who know each other, while messages from advertising companies and strangers were seen as intrusive and unwelcome [10]. Studies of teenagers' texting habits revealed that they used texting to coordinate activities with others, initiate communication, and simply to chat $[8,10,20]$; however, within this, they experienced challenges in understanding the intent behind messages as well as an evolving 'texting language' $[8,10]$. Texting was also highly valued because teenagers could perform multiple tasks while communicating with friends $[1,8]$. In addition to this, we also now see reports of teenagers 'sexting' where they text sexually explicit messages or revealing photos of themselves to others [27].

\section{Instant Messaging}

Instant messaging (IM) is another popular communication medium amongst teenagers. Studies have shown that, as of $2007,82 \%$ of the teenagers who used the Internet also used an IM client to communicate with friends [19]. Teenagers' typically used IM with their school friends (as opposed to people they might meet online) and it allowed them communicate at nearly all hours of the day [9,11]. IM was used for socializing, event planning, and joint schoolwork from home [9]. Within these activities, teenagers would multi-task what they were doing, and also multi-task their conversation [9]. While using IM, teenagers were concerned about others looking over their shoulder because they often used computers in public home locations [20]. They also expressed privacy concerns about messages being saved on the computer and read by others and would carefully use IM status indicators and messages to enforce their autonomy and provide awareness of presence [9].

\section{Social Media and Social Networking Sites}

Teenagers also make heavy use of social networking sites such as Facebook. Again, they are primarily used by teens to connect with friends whom they already know as opposed to strangers [1,4,22]. Social networking sites were found to be used by teens to build stronger connections, express one's self, participate in work, care for others, gain knowledge on social contacts, and maintain their existing relationships $[1,4,10,18]$. For many teenagers, the benefits of social networking sites were deemed to be so strong that they often outweighed privacy concerns [4]. Benefits include building reputation, popularity, social status, and connection [4]. According to studies by boyd in 2007, teenagers who do not participate in social networking sites can be divided into two categories: disenfranchised teens and conscientious objectors [4]. Marwick and boyd discuss how teenagers use social media to engage in discussions of "drama," interpersonal conflicts similar in nature to bullying, gossip, and relational aggression but with their own distinct connotation [21]. In a study of parents in 2011, Yardi and Bruckman found that parents try to create rules about computer and social media usage but it can be hard to enforce them [27]. Parents worry their children are going to say something or get involved in a conversation that can have devastating consequences, especially because of the permanency of some communications [27]. Parents typically want visibility in the technology their children use: some parents want their children to know their online behavior is being watched and other parents want to watch surreptitiously, waiting for children to make a mistake and expose a "teachable moment" [27].

\section{Video Chat}

Several studies have investigated how adults and children (non-teenagers) use video chat to connect with family and friends. These have shown that it is often challenging to maintain calls long term because of infrastructure issues and software crashes [2] but many people "put up" with these because of the benefits of video chat. There are also challenges in knowing when people are available and willing to use video chat as opposed to other technologies like the phone $[2,13,16]$. Despite these issues, people find great value in video chat systems because they allow them to feel more 'present' with their remote family or friends $[6,24]$ and they are able to see body language and other visual cues depicting emotion $[6,16,24]$. Because of the unique benefits of video chat, people are more likely to accommodate distance in their personal relationships [6]. Many people are concerned about their appearance over a video link [7], yet this diminishes with usage [6].

There also exists a phenomenon where people will leave video connections open for longer periods of time and focus on sharing activities over distance rather than just conversation $[6,13,16,24]$. This may occur in a single location, but many people prefer to move around their home [6,24]. Grandparents watch their grandchildren play for long periods of time [13], parents and their adult children perform activities together such as cooking [6], adults may watch television together $[6,24]$, and some long distance partners engage in sexual acts over the video link [24]. Given the trend of people using open video connections, several systems have been designed to better support these needs and the sharing of activities rather than just conversation. These have included always-on video links between one or more households [14,15] and even mobile devices [23]. We have also seen the design of systems targeted for specific activity or life situations such as reading between grandparents/children $[25,26]$ or shared activities between divorced parents and their children [28].

Thus, while there has clearly been a large amount of research in the space of video chat, there are no studies 
specifically targeting teen use. The notable exception comes from Kirk et al.'s study, which contained two teenage participants (of 17 in total) [16]. Here they state that they sensed teenage usage of video chat was very different from adult users, but with the small sample were unable to expand deeply on this. This provides further motivation for our current study. Closely related to our work is a study by Inkpen et al. that describes how pre-teen girls (aged 9 and 10) used an asynchronous video messaging system [12]. Uses included conversing, show and tell, sharing activities, and play-acting / performing. Our study illustrates how these and more occur during synchronous video exchanges by teenagers.

\section{STUDY METHODOLOGY}

We conducted an interview study with teenagers who used video chat to understand their usage of the technology.

\section{Participants}

We recruited twenty teenage participants (10 male and 10 female) through snowball sampling, word-of-mouth, and by posting ads on sites such as Facebook and Craigslist. Four teenagers were between the ages of 13 and 15, and sixteen were between the ages of 16 and 18. Participants varied in terms of how frequently they used video chat. Fifteen were frequent users and would use video chat weekly, while five were infrequent users who used video chat every 2-3 months. The frequent users helped us understand the motivating factors behind video chat usage and the ways in which video chat tools were used. The infrequent users gave us insight into why teenagers may not use video chat frequently and what technologies were used instead of video chat. Twelve participants had used video chat for over a year and the other participants had all used video chat for several months to a year. All participants lived in a major metropolitan city in North America and were from middle class families of a variety of ethnicities.

\section{Interview Method}

We conducted semi-structured interviews with each participant individually in Spring 2012. Interviews lasted between 60 and 90 minutes. Prior to the interview, each participant was given an outline of what types of questions to expect and were told that data would remain confidential and anonymous. It is our university's ethical policy to breach confidence in situations involving potential suicide, child abuse or violence; no such situations arose. Parental consent was obtained for all interviews; however, parents were not present during the interviews and they did not see their teenager's data. We hoped this would allow the participants to openly discuss their technology usage.

Five interviews were conducted in person at local coffee shops, six interviews were conducted in person at the participants' high schools, and the remaining were conducted at the participants' homes. Each participant was paid \$20 for the interview. Interview questions asked the participants about their communication practices using video chat, the motivation behind these practices, and their preferences on systems and devices for video chat usage. For example, questions included "Which video conferencing tools do you use?" and "When do you use video chat?" We also asked participants to tell us stories about memorable video calls and their more typical calls.

The interviewer was a trained, undergraduate student researcher in her early $20 \mathrm{~s}$. In retrospect, we feel this helped considerably in gathering information from participants. The participants repeatedly engaged with the interviewer in conversations outside the topic of the interviews (e.g., pop culture, activities at school), which suggests that they saw her more as a peer than a parental figure. This latter situation could have easily arisen if the interviewer was an older, more senior researcher. For future studies with teenagers, we certainly advocate our approach.

We also had the first seven participants (4 females, 3 males) (3 under 16 years of age) complete a private online diary about their communication routines over a 3-week period where they received $\$ 1$ per daily diary entry. We had hoped this would provide more 'in-the-moment' data, yet we only received 65 entries across the 7 participants (average 8 per person) and the content did little to inform our findings. We suspect that our monetary incentive was not high enough and, perhaps more importantly, the teenagers were less interested in doing a repeated activity over a longer time period. Because of this, we do not report on data from the diaries; we mention it here as a consideration for future studies though.

\section{Data Collection and Analysis}

We kept handwritten notes for all interviews along with audio recordings. We transcribed audio recordings and then performed a thematic analysis on the transcribed data (diaries and interviews). Our analysis revealed several themes that form the focal points of our results and the subsequent sections. In our results, we list representative quotes along with the gender and age group of the participant. 'Older' refers to teens 16 years of age and older and 'Younger' refers to teens under 16 years of age. We have chosen to not include exact ages next to quotes to further anonymize our results, given the sometimes sensitive nature of participants' comments.

Our results first discuss the general practices that teens had for video chat, including who they talked with, how video chat compared to their uses of other technologies, and how they initiated video calls. Following this we look at the variety of activities that occurred over video chat including both 'focused' and 'open' activities. Next we outline privacy and trust issues that arose for the teens.

\section{GENERAL PRACTICES FOR VIDEO CHAT}

Our participants used a variety of video chat systems and devices. Four of our participants used laptops consistently while eight participants used laptops along with other devices such as iPhones, iPods, and desktop computers. Three participants consistently used desktop computers and 
two of these also used iPods. Two participants reported constantly using their iPhones to participate in video chats and the remaining participant reported to use an iPad and iPhone. Fourteen participants used multiple video chat systems where the most common was Skype $(18 / 20)$ followed by FaceTime (10/20), Tinychat (3/20), MSN Messenger (3/20), and Google Hangouts (1/20). All participants favored being able to use a portable or mobile device for video chatting such as a laptop, tablet, or phone. However, one participant did explain that he had to hold his iPhone at awkward angles during video calls.

Desktop computers used for video chatting were often located in a central area of the home where other family members also had access to it. Areas like the office, living room, and kitchen were the most common areas to keep a desktop computer. Teenagers using laptops would also stay located in one location for the majority of a video call. Most participants who had access to a laptop would keep it in their bedroom and calls were often initiated from this location. Some participants reported moving laptops around the home based on their location.

\section{Who Was Called and When}

For those who used video chat frequently, it was primarily used as a tool to connect with a close group of friends, regardless of how close they lived. While they would regularly have a large number of contacts in their video chat contact lists (e.g., 50-100), they would really only video chat with a select few with whom they were comfortable calling. This included close friends, boyfriends, or girlfriends. Participants also typically had very few family members on their video chat contact list, e.g., less than five.

Those participants who were infrequent video chat users would only use the technology with family members who lived far away. In contrast to frequent users, they preferred to talk with friends who lived nearby in person and made comments such as, " "why would I chat with my friend over Skype, when I can just see her in person." This may also be explained by the mobility of our infrequent video chat users: all had a driver's license and could drive as needed to visit friends. Not all of our frequent users had this luxury.

"Before, when I had [Skype], I didn't have a car or anything and it was just like, after school, just like talk to a person. I think it's more fun if you can see the person's face, like you know, you can see what they're doing" -P14, Older Female

Most participants did not trust people who were anything less than an acquaintance when it came to video chat. Yet, in the extreme, we did have one participant who reported regularly conversing over video with people she had met online and did not know in person. She explained to us that these online friends acted like a support group to whom she could 'vent'. With her online friends, she did not worry about gossip spreading or judgment because they did not have mutual friends in common, she did not see them in person, and they did not go to her school.
Video calls typically lasted between thirty minutes and one hour, though some reported calls of several hours where connections were left open. We discuss this in detail later.

\section{Initiating Video Calls}

Only one participant had scheduled video chat sessions. This was with an extended family member where the participant's mother would schedule a time over email for her daughter to video chat with her aunt. For all others, video chat was a spontaneous activity that occurred at varying points in the evening or on the weekend. This is likely because video chat usage amongst teenagers was tied more to local friends than extended family.

"I don't really need to like schedule a time to like talk to my friends, like I see them every day at school so it's like if they want to talk more I guess it's like, there should be like a reason, it's not like 'Okay, six tonight and every Monday'. It's just cuz like, yeah, I guess if like they want to talk or something, then you just sporadically be like 'Hey I want to talk' and then yeah. That's why I guess it's not as scheduled" - P15, Younger Female

Participants reported logging into their video chat system and seeing who was online before making a video call. Skype and MSN Messenger, for example, reveal the status of the user whether they are online, away, or offline. This online presence indicator was enough to prompt a video call for half of our participants. The other half said that their online status did not indicate their availability and at times, it did not indicate the availability of others. It is worth noting that each participant was actively trying to discern whether or not the online status indicated availability though. If a contact was not online, participants said that they would send them a text message, quick phone call, or Facebook message to tell the other person to go online.

"People usually use Facebook over Skype so they'll message me and say what's up" - P4, Older Female

\section{Video Chat Compared to Other Technologies}

As a comparison, we asked participants about their use of communication technologies other than video chat and found fairly specific uses. Participants commonly used Facebook when they were bored or wanted to 'catch up' with people quickly by reading status messages, looking at photos, or posting wall comments. Thus, it mostly served to fulfill a 'browsing' need, rather than direct communication. As mentioned, Facebook was also used to find people to video chat with. Text messaging was primarily used for exchanging short and quick messages with friends. It was often the technology our participants turned to if they did not want to feel obligated to have a long conversation with someone.

"Text can be short and quiet but um, Skype really requires you to sit down and give it a lot of attention. Calls can go on from anywhere from like thirty minutes to a couple of hours... If it's something, like, really important than I'd 
rather say it to them in person and if, in that case, Skype is accessible then I would use that." -P16, Older Male

Similar to other studies [24], video chat played a communication role that was different and beyond other technologies. It was most often not the most frequent communication technology they used, however, our participants unanimously explained that video chat was the closest thing to face-to-face communication. It allowed them to see what the remote person was actually doing and to 'hangout' with them. Participants also felt they could more easily empathize with the recipient of the call because their facial expressions were visible and it was less likely that a conversation was taken the wrong way. This was useful when discussing sensitive topics (e.g., during arguments). Participants also valued seeing facial expressions when telling jokes or showing something funny. What was striking was that video chat was not first and foremost seen as a way to feel closer to the remote person (like was found for adults $[6,16,24]$ ) since the teenagers would see each other at school typically daily.

"I enjoy that one, you can catch up and chat with them. It's not just like a phone where you hear them, like you hear a bang and are like "What Is that?" but if you video chat you can see them and like see what they're doing... Just for the fact that you can see their facial expressions and if you tell a joke you can see if they actually did laugh or if it's a fake laugh ... if you don't want to cross boundaries with someone, like say you're discussing a topic with someone that is kind of iffy. You can tell by their face if they're like 'Oh, what's this person saying?'... Like conversations that could be taken in a good way or go completely downhill." P6, Older Male

Although the participants preferred video for conversing, users expressed irritation with problems such as a lack of Internet connection (e.g., FaceTime over Wi-Fi), software glitches, poor audio quality, or picture distortion. Several teenagers said that if video transmission started to lag or interfere with audio, they would end the video connection in preference for a clear audio-only conversation.

\section{ACTIVITIES DURING VIDEO CHAT}

All of our participants divided their attention between multiple activities at the same time while on a video call. Many of them reported to simultaneously browse the Internet, chat on social networking sites, or watch television while video chatting. For most of the participants, multitasking was a habitual behavior. The activities and types of conversations carried out by the participants over video chat fell into one of two categories: focused conversations or open connections. This reflects Kirk et al.'s categorization [16]. Within each category, we learned about several nuanced activities that occurred.

\section{Focused Activities}

Focused conversations and activities were reported by all of the participants. For some of them, it was a sporadic call where there was a sudden desire to share news or to show something. For others, these focused activities would occur during an existing video call.

Show and Tell. Show and Tell activities occurred most often amongst our participants. Whether it was clothing or personal accomplishments, teenagers enjoyed sharing these things with one another and compared it to having friends in the room. One teenager expressed excitement and happiness as she told us a story about showing her friend some new clothes that she bought.

"I'll be in my room and I'll just sit on my bed with a Skype call on and I'll show them some stuff like if I got new clothes or something... we always like look at our outfits and stuff... It's like [having] a new best friend in my room." - P1, Older Female

The framing of the camera sometimes made it difficult for the teenagers to show the recipient exactly what they intended. In this case, they would spend time lining up the camera accordingly. 'Show and Tell' calls could occur in virtually any room of the house, where some locations may be less conducive to laptop or phone placement, e.g., a bedroom. One participant described how his friend called him on FaceTime from the kitchen after cooking:

"The last time my friend wanted to show me something he was trying to cook and it went completely awful and he was telling me how he spilled and it was all over the floor and he was going to clean it up, he was going to get the dog to eat it. Then the dog started eating it and he was showing me over FaceTime, kind of funny. " - P6, Older Male

Sometimes the location of the call itself was the point of the 'Show and Tell' call. The same participant talked about a call he received from someone in the washroom:

"Uh one of the times I just couldn't stop laughing at this...he FaceTimes me and I didn't really pay attention to what was in the background and he had it so I could just see his face and then he paused it on the face and flushed [the toilet], and played it as he flushed it. It's potty humor, I know but it was just so random. - P6, Older Male

Gossip. Another common 'focused' activity done by teenagers over video chat was gossiping. Here teenagers actively conversed with their friends where they would talk about other friends from school, boyfriends or girlfriends, parents, siblings and more. This type of conversation was beyond simply talking about one's day and focused more on interpersonal relationships. Marwick and boyd refer to this type of talk as part of teenager "drama" [21]. Three participants talked about gossiping that turned into rumors being spread about them.

"I used [Skype] the last time to vent to [my friend] about the problems I was having with my boyfriend. I just kind of needed to get it off my chest and didn't really want him to see that I used that and I felt a lot better." - P4, Older Female 
"I think girls gossip a lot [over video], but guys gossip maybe ten times more. I don't know if it's just our generation, but we talk a lot. We'll like pick somebody and we'll all like have a couple of things to say about that person and then okay that guys done, how about this person... In a sense, I guess you can think of it as bullying but it's kind of like we're venting out whatever we have to say." - P13, Older Male

Participants expressed keen interest in topics that revolved around peers or 'theatrical' occurrences in their daily lives. What made video the best tool for this activity was the instant gratification of venting to friends without having to travel distances. The video systems allowed our participants to see their friends' expressions so they could laugh with them when they mocked others. This would be difficult to detect over text and even a phone call.

Flirting, Nudity, and Sexual Acts. Some participants also talked about flirting with others over video chat. In these cases, participants said they would be talking directly with another person and as the conversation continued, both genders would begin to 'show skin', and in some cases, even masturbate with one another over video chat. This typically occurred late at night in the participants' bedrooms. We note that only older teens (4 male, 1 female) brought this up. Participants explained that sex talk and activities over video were better than on the phone because you could actually see the person doing the activity.

"Yeah, well my friends try to get girls to show [their breasts] ... like take their shirt off." - P11, Older Male

"A lot of guys brag about how they get all of these bitches and what not, like 'oh yo, you should see what we did' ... [there's] the casual strip teases and what not. Just like showing each others' junk, I guess you can call it ... [Sex talk is] easier, isn't it? with video, cuz you can see each other. It's like, some parents are really strict and they don't want you to see each other then why not just do it on the video. You got your room locked, you have your privacy." P13, Older Male

A female participant told us a similar story about being asked to strip and dance for a boy over video chat.

"I remember like on MSN, a guy would ask me to go on and stuff, but then he'd be like 'Ooh, do something else', but like I was kind of uncomfortable because I was only 13 or 14 so I was like 'Nooo'... He was my age and just pervy, more or less. So he just wanted me to, I don't know, like dance around." -P14, Older Female

Two participants shared stories with us about their friends who would make video calls while naked or with the intention to get naked:

"I've had some friends who intentionally go naked [on Skype] just to liven up the conversation, I guess" - P12, Older Male
"A friend of mine, her and her friend, in front of a web cam played strip poker with like two other guys on the opposite web cam. And they just, boobs and all, just straight on the web cam." -P14, Older Female

\section{Open Connections \& Activities}

Like families with children and long distance couples $[6,13,16,24]$, the teenagers in our study also kept their video chat calls open for longer periods of time where they would engage in a variety of activities visible on the video channel. In these cases, they wouldn't necessarily be engaged in focused conversations or acts with others like were the case for the previously described activities. Instead, they would simply be 'hanging out' together over video chat, much like friends would be together in person. This type of open connection would typically last longer than more focused calls.

"[I] just set [Video Chat] up and I could be doing my homework, eating food, watching TV [while] talking to someone on Face Time." - P6, Older Male

Our analysis showed several interesting situations revolving around these 'open connections.' We outline each next.

Multi-Person Calls. Three participants described their practices of video chatting with multiple friends at the same time. In this case, each would connect from his or her own home using Group Skype calling. While one might expect this to be a 'focused activity,' participants described it as an open activity where they would fluidly move in and out of conversation with people in the group. Here they did not feel an obligation to stay in front of the video chat software. Instead, they felt freer to watch television in the background or get up to move around the house without making an announcement. Teenagers were more inclined to watch others communicate until it was their turn to talk.

For example, one participant described being in a multiperson call where some of his friends started to flirt with others in the call. He expressed feeling 'left out' in this situation. This exclusion from the conversation gave him opportunities to go to and from the computer as he pleased. As he described, he would often go into the kitchen to grab snacks as the video call continued. Another participant also reported similar feelings of neglect during a multi-person conversation. He explained the difficulty of talking over the other participants in the call and the frustration that could arise. Instead of staying on camera, he would wait his turn to talk and in the mean time did not feel tied to the computer as his friends carried on the conversation. In this way, teens were able to 'hangout' in a multi-person call.

"I've talked to 5 people at once.... It's not exactly fun because everybody talks over each other." - P10, Younger Male

Teenagers were more likely to participate in group calls later in the evening or on weekends because others were more likely available at these times. For example, one 
participant reported having a multi-person conversation with a friend at a slumber party. Teenagers were also more likely to participate in multi-person conversations when using software such as Google Hangouts and Tinychat. One participant used Skype to connect with multiple people via video, but unlike the other software, multi-person calls in Skype are not free. As such, this participant described how she took advantage of Skype's free trials:

"You have to pay for conference calling [over Skype] but you can get a seven day trial... So I'll just create a new email and a new Skype... I probably have about 52 Skypes already but only one main one that I use."- P1, Older Female

Homework. Six participants (3 Younger, 3 Older) used open calls while working on school coursework. They would leave the video chat running while completing their assignments on the computer. During this time, they would multitask and look up multiple websites in different web browser tabs. Occasionally, these participants would return to the video call and ask their friend a question or check up on progress. Overall, convenience was the main reason teenagers chose to do their homework over Skype rather than in person. For example, one teenager told us a story about doing homework in the evening when his parents were not able to drive him to a friend's house:

"[With Skype] You have the visual aid, you can show them what you've done rather than just try to explain it... It's the convenience factor, being able to do it from home. Let's say I'm at home, it's like after dinner, usually parents are just like 'Okay we're really not going to be leaving the house at like seven or eight o'clock' but you do have like this difficult [homework assignment]. It's just again the convenience factor you don't have to leave the house you can just be like 'Okay let's go on Skype, we'll figure this out' rather than you have to drive fifteen to thirty minutes, like wherever you may live in town to come help me with this problem" -P16, Older Male

Performing. At times, participants felt the need to share activities with others over for video chat. Four participants shared stories with us about 'performing' over video chat. For example, one participant told us a story about how he, along with his friends, would skateboard in front of the camera and get feedback or encouragement on their tricks. In this case, video chat took place on the participant's iPhone over FaceTime. The friends enjoyed this activity and video chat allowed them to be together for it remotely.

"[My friend and] I skate board so like sometimes he'll go in his garage and he'll show me a new trick he learned, like he'll set his camera up and he'll try it a bunch until he learns it." - P6, Older Male

Despite the benefits, setting the camera up for these situations and properly framing the video was a challenge. The participant ran through his trick a few times, positioning the phone at different angles before lining the camera up in the correct view to get feedback from his friends. The convenience in showing something instantaneously was the main reason why teenagers preferred to perform over video chat rather than in person. Other participants shared stories about dancing in front of the camera or watching their friends play instruments over video chat.

"Sometimes I dance [over video] but that's just cuz it's hilarious... It's more convenient, so it's just like, if the person lives a while away you're just like 'Okay go on [Skype] and I'll show you'." - P14, Older Female

"My friends...practice [guitar] over Skype...It's the ease of use; you don't have to bring the guitar to their house. You can just be like 'I just want to brush this by you and see what you think' and you can quickly show them... It's the convenience factor. It's just way easier to just do it over video than to have to leave the house." - P16, Older Male

Gameplay. Two participants talked about using video chat while playing games either on an external device or on the same computer used for video chatting. Although their interactions were minimal, when needed, they shared tips with one another on how to complete levels and shared the excitement of completing a challenge.

"A lot of people when they play video games like to have a mic to chat with their friends and then if you don't want to go out and purchase a mic it could be easier to just have your laptop set up next to your equipment and be able to talk to them ... it's just like having them in the room with you." - P16, Older Male

\section{PRIVACY AND TRUST}

Although we initially thought that video chat would raise serious privacy concerns amongst teens, participants generally felt comfortable and at ease with the technology. This was largely because they typically only conversed with those people who they knew well. However, participants did describe challenges with appearance, the chance of parental invasion, and background viewers.

\section{Room and Personal Appearances}

Eleven of our participants said that they were concerned about the appearance of the location being captured over video chat and what this might do to their 'image.' Yet rather than cleaning up an area, participants explained that they could simply tilt the camera away from a mess.

\section{"You don't want to be called a slob." - P5, Older Male}

"If you don't want people seeing a certain area, you just kind of tilt the camera one way and just leave it there." - P6, Older Male

Some participants used desktop computers that were situated away from a wall, and did not have the luxury of tilting the camera. In this case, it was even more important for them to clean an area prior to initiating a video call. 
"[When we're on Skype] I feel like he's at my house and obviously if I bring someone over I'm not just gunna have, you know, my underwear lying around. I like to clean it up." - P14, Older Female

Eleven of our participants said that were concerned about their own appearances on camera; this is similar to findings with adults [7]. Participants were more likely to "beautify themselves' before having a conversation with the opposite sex. Several people said that looking nice on camera made them feel better about themselves and gave them more confidence. One participant described how her appearance depended on which friend she was connecting with:

"Sometimes I do my makeup a little bit because [not wearing any] makes me feel washed out [and] like crap. But it depends who I'm on [Skype] with because if it's like [friend's name] then I don't care. I'll be like 'Oh I'm not wearing any make up' [and] she won't be wearing any makeup [either] but she looks gorgeous all the time so yeah. I just sit over here and just like hide." - Pl, Older Female

Another participant also talked about the challenges of her video chat system 'controlling' her appearance, rather than being in control of it herself:

"The worst is when [Skype] crashes or the picture is frozen, and you can just hear the person... The problem is that it freezes on like the ugliest face ever." - P9, Older Female

\section{Parental Invasion}

Parental invasion was an issue with our participants for any communication technology. Teenagers who used social networking sites were okay with using a computer in a populated area and would conceal their information by changing their privacy settings or blocking out family members from seeing their photos or posts on their social networking accounts. Yet video chat presented a different challenge: Our participants had to worry about parents overhearing or overseeing video calls and told us they would often carefully think about how to hide certain chats from their parents. In particular, this included gossiping, flirting, and sexual activities. Naturally, teenagers preferred to perform these activities in private areas because they were afraid of being caught and punished. Participants who did not have access to a computer in a private area showed frustrations and wanted a computer in their bedroom.

"I usually won't turn my camera on if I'm with my family. I really like having the privacy, myself, when I have the camera on... If you're having a private conversation with your friends, like a lot of that stuff you just wouldn't talk around your family or you wouldn't talk around other friends and it's the same thing, like it doesn't matter which platform you're saying it on, you still want that privacy." P16, Older Male

Only two parents explicitly regulated the computer usage of participants in our study and tried to carefully watch what their teenage children did online. These were the parents of two thirteen-year-old males. Both sets of parents had the passwords for their teenager's social networking sites and would implement curfews or set times when their teenagers could use the computer. One participant told us a story about how his parents grounded him when they found a conversation that he had with a friend over Facebook. Conversely, nobody reported being disciplined because of conversations they had over video chat.

\section{Background Viewing and Listening}

Teenagers showed concern about talking to others over video chat and not always knowing who was in the vicinity during a call. Due to camera restrictions, only a limited view of the area was visible. Our participants explained the ease of controlling the angle of the camera to focus on less distracting areas like a wall. Some apprehension was noticeable here, as constricted views of the room raised privacy concerns for the teens and held them back from openly talking about deep subjects. They also gossiped less when they thought others might be able to hear them.

"Like as I was saying you can't be as open [over Skype] because you never know if someone else could be um, in the room with them like listening... Because you can't see the whole room."- $P 8$, Older Female

Interestingly, none of our participants brought up video framing and background viewing as a concern while participating in sexual activities over video chat. We suspect that this was because sexual activities always occurred in the evening after parents were asleep and they were done only by participants who had the ability to video chat from their bedroom. Six participants openly talked about their concern of hackers connecting to their camera and watching them as the changed clothes or slept. All of these participants took preventative measures such as not adding strangers to their video chat accounts or by putting tape over their video camera when it was not in use.

\section{DISCUSSION AND CONCLUSIONS}

We now compare our findings to previous studies of teenagers' technology usage and video chat studies of adults/kids. Following this, we discuss design implications.

\section{Comparison to Teen Messaging}

Like IM and texting $[8,9,10]$, teenagers use video chat primarily with their friends and highly value the ability to multi-task while doing so. Multi-tasking even takes the form of multi-person video calls, which is also found in IM [9] but not possible over text messaging. Video chat also allows teenagers to converse and 'hangout' with their friends outside of typical 'in-person' socializing hours, as found with IM and text $[8,9,10]$. Participants described the initiation of video calls in a similar manner to how past studies described the initiation of IM chats where availability status indicators and messages were carefully used and watched [9]. In this way, teenagers regulated their autonomy with video chat, much like IM [9]. 
Like IM and text $[8,9,10]$, video chat can be done outside of the radar of parents. This was especially the case for teenagers who had their own laptop or phone that supported video chat because they could use them in their bedroom. Teenagers who could only video chat from public home locations were concerned about parents looking over their shoulders during a call; this is the same as studies of IM [20]. With IM, teenagers were also concerned about others reading saved copies of chat messages after the conversation [9]. With video chat, privacy concerns were typically 'in-the-moment' because video chat systems do not save content (unless third party software is used).

\section{Comparison to Adult and Child Video Chat}

Like prior reports of adult use of video [13,16,24], teens shared the benefits of seeing body language and facial expressions during a video call. Teenagers also participated in open video link connections over extended periods of time, similar to adults and children [13,16,24]. Yet the difference with teenagers is that calls were nearly always spontaneous. This contrasts with typical behaviors by adults where video calls were most often scheduled [13,24].

Pre-teen children were found in prior studies to engage in 'Show and Tell', 'Activity Sharing', and 'Performing Acts' over asynchronous video [12]. We saw these same practices occur for teenagers over synchronous video. Yet teenagers also performed different activities: Similar to long-distance couples that use video chat [24], some teenagers performed sexual acts over video links.

Our results also showed that teenagers have different notions of 'distance' as compared to adults. Adults typically use video chat with family members who live in different cities, across country, or across the world $[13,16]$. Teenagers have a much more localized sense of distance. That is, teenagers would most frequently participate in video chats with other teens in their own neighbourhood. This is mainly because many teenagers do not have the luxury of driving to meet with others in town. They also often face parental restrictions about what time of day they can leave home. In some cases, it can also be cumbersome to travel with objects in order to show them or use them as part of activities (e.g., new clothes, musical instruments, skateboard ramps). In these situations, video chat provides a convenient alternative for hanging out with friends. It also means that video is not used first and foremost to feel 'close' to someone since teenagers see each other in person typically the next day at school. This contrasts adults where the focal point of video calls is to feel close to the remote people given the long distances $[6,16,24]$.

Existing studies show that multi-person calls are not typical amongst adults $[2,6,13,16]$. Our results showed that teenagers engage in them more frequently. We suspect this is the case because of teenagers' needs to hangout rather than use video chat to feel close. The need for feelings of closeness amongst adults creates a preference for more intimate, one-on-one calls [6].
Teenagers showed little patience for bad connections. When the Internet connection was slow, teenagers would drop the video feature and continue an audible conversation only, or they would drop the call all together. Conversely, adults often endure slow connections in order to get a glimpse of their loved ones [6]. This suggests again that teenagers' desire to see the remote person is not necessarily about feeling close to them; instead, it is about hanging out and, if video fails, they will quickly switch to another technology.

\section{Design Implications}

While we feel it is beyond the scope of this paper to provide full design ideas as to how one might design 'better' video chat systems for teens, we do discuss several challenges that we think are pertinent for this design area.

First, there are clearly issues that teenagers face with video chat technology. Teenagers move between locations (both inside and outside the house) and need to capture a variety of activities on camera. Here camera framing is an issue as is laptop or phone placement and movement. In multi-party calls, it can be hard to hear over people despite the desire to have such calls. Teens are also concerned about knowing what is captured on camera and who might not be captured but still able to see or hear the video call. For the most part, these all suggest better cameras with wider fields of view, multiple cameras, better placement options for cameras, etc.

Yet looking at the teenagers' perspective of wanting to maintain a large degree of privacy, a small laptop screen and single camera lend themselves more naturally to not being seen or overheard by others. Clearly this is a challenging paradox that any future design needs to address. Unlike social networking sites, teenagers cannot easily block parents' access to video chat calls by adjusting privacy settings and such. Parents can simply stand within earshot or a visible distance of the screen. Instead, physical obstacles and architecture (e.g., a bedroom) play a clear role in regulating privacy when it comes to teen video chat.

Second, from the parents' perspective, there are other issues relating to teenager use of video chat. While we did not study parents or their rules for video chat usage, past studies show that parents are concerned about what their children do online and fear they will do something with lasting consequences [27]. For example, video chat makes it easy for teenagers to perform sexually explicit activities that are viewable by others. This clearly puts them at risk. Yet it is a different type of risk than is commonly taught at schools around sexual education and the promotion of abstinence or safe sex. Parents may need to worry less about 'real world' sex, but instead be fearful of cybersex and public viewing or recording of such acts. Thus, yet again, we see a paradox: Teenagers want technologies that support 'private' activities with their friends, while parents likely do not want their children engaging in such activities.

However, video chat is also used by teenagers for more positive activities such as doing homework together, 
visiting with friends when one is not able to travel, etc. Teenagers can stay 'under the roof' of their parents yet still engage in activities with their friends. This could easily help alleviate likely parental concerns associated with 'going out,' such as drunk drivers, pre-marital sex, physical violence, etc. This suggests that the best way to manage the use of video chat systems is through social exchanges and education. For example, parents should be aware of the benefits and risks associated with video chat and attempt to openly discuss them with their teenage children. Alternatively, designs focused on providing parents with means to monitor teenage video chat activities would likely not work. Teenagers would simply find workarounds.

This leaves interesting design and social challenges for the topic area. Our own future work will continue to explore the design of video chat systems for teenagers as part of our broader focus on video systems for families.

\section{ACKNOWLEDGEMENTS}

We thank the Natural Sciences and Engineering Research Council of Canada and the GRAND Networks of Centres of Excellence for funding this research. We also thank the reviewers for their very helpful revision suggestions.

\section{REFERENCES}

1. Agosto, D., \& Abbas, J., High School Seniors' Social Network and Other ICT Use Preferences and Concerns, Proc. ASIST, (2010)

2. Ames, M., Go, J., Kaye, J., Spasojevic, M., Making Love in the Network Closet: The Benefits and Work of Family Videochat, Proc. CSCW, ACM Press (2010).

3. Agosto, D., \& Abbas, J. Teens and Social Networking: How Libraries are Responding to the Latest Online Trend, Public Libraries, 48(3), (2009), 32-37.

4. boyd, d., Why Youth (Heart) Social Network Sites: The Role of Networked Publics, In Buckingham, D. (Ed), MacArthur Foundation Series on Digital Learning, MIT Press (2007).

5. Brown, J. Growing Up Digital, Change, 32(2), (2000), 10-20.

6. Brubaker, J., Venolia, G., and Tang, J. Focusing on Shared Experiences: Moving beyond the camera in video communication, Proc. DIS, ACM Press (2012).

7. Filho, J., Inkpen, K., and Czerwinski, M. Image, Appearance and Vanity in the Use of Media Spaces in Videoconferencing, Proc. GROUP, ACM Press (2009).

8. Grinter, R.E. and Elridge, M. y do tngrs luv 2 txt msg?, Proc. ECSCW, Springer (2001), 219-238.

9. Grinter, R.E. and Palen, L., Instant messaging in teen life, Proc. CSCW, ACM Press (2002), 21-30.

10. Grinter, R.E., Palen, L., and Eldridge, M., Chatting with Teenagers: Considering the Place of Chat Technologies in Teen Life, Transactions on CHI, ACM Press (2006).

11. Gross, E. Adolescent Internet Use: What we expect, what teens report, Applied Developmental Psychology, 25, Elsevier (2004), 633-649.
12. Inkpen, K., Du, H., Roseway, A., Hoff, A., and Johns, P. Video Kids: Augmenting Close Friendships with Asynchronous Video Conversations in VideoPal, Proc. CHI, ACM Press (2012).

13. Judge, T.K., \& Neustaedter, C., Sharing Conversations and Sharing Life: Video Conferencing in the Home, Proc. of CHI, ACM Press (2010).

14. Judge, T.K., Neustaedter, C. and Kurtz, A., The Family Window: The Design and Evaluation of a Domestic Media Space. Proc. CHI, ACM Press (2010).

15. Judge, T. Neustaedter, C., Harrison, S., and Blose, A., The Family Portals: Connecting Families Through a Multifamily Media Space. Proc. ACM CHI, (2011).

16. Kirk, D., 2010. Home Video Communication: Mediating 'Closeness', Proc. CSCW, ACM Press (2010).

17. Lenhart, A. Teens and Online Video: shooting, sharing, streaming, and chatting, Washington, DC: Pew Internet \& American Life Project (2012).

18. Lenhart, A. Teens, Kindness and Cruelty on Social Network Sites, Washington, DC: Pew Internet \& American Life Project (2011).

19. Lenhart, A., Madden, M., Macgill, A., and Smith, A. Teens and social media, Washington, DC: Pew Internet \& American Life Project (2007).

20. March, W. and Fleuriot, C. Girls, Technology and Privacy: "Is my mother listening?", Proc. CHI, ACM Press (2006)

21. Marwick, A. and boyd, d. The Drama! Teen Conflict, Gossip, and Bullying in Networked Publics, Symposium on the Dynamics of the Internet and Society, (2011).

22. Marwick, A.E., Murgia-Diaz, D., and Palfrey, J., Youth, Privacy, and Reputation, Berkman Center Research Publication, No. 2010-5, (2010), 4-65.

23. Neustaedter, C. and Judge, T. Peek-A-Boo: The Design of a Mobile Family Media Space, Video, Proc. Ubicomp, Springer (2010).

24. Neustaedter, C., and Greenberg, S., Intimacy in LongDistance Relationships over Video Chat, Proc. CHI, ACM Press (2012).

25. Raffle, H., Ballagas, R., Revelle, G., Horii, H., Follmer, S., Go, J., Reardon, E., Mori, K., Kaye, J., and Spasojevic, M. (2010) Family story play: reading with children, Proc. CHI, ACM Press (2010).

26. Raffle, H., Revelle, G., Mori, K., Ballagas, R., Buza, K., Horii, H., Kaye, J., Cook, K., Freed, N., Go, J., Spasojevic, M. Hello, Is Grandma There? StoryVisit: Family Video Chat and Connected E-Books, Proc. CHI, ACM Press (2011).

27. Yardi, S. and Bruckman, A. Social and Technical Challenges in Parenting Teens' Social Media Use, Proc. CHI, ACM Press (2011).

28. Yarosh, S., Cuzzort, S., Mueller, H., and Abowd, G.D., Developing a Media Space for Remote Synchronous Parent-Child Interaction, Proc IDC, ACM Press (2009). 